\title{
Factors Associated with Stress and Stressors among Nurses working in Critical Care Units at Muhimbili National Hospital in Dares Salaam, Tanzania, East Africa
}

\author{
Article by Sithembile Majuta \\ Nursing, Texila American University, Tanzania \\ Email: trustworthymajuta@yahoo.com
}

\begin{abstract}
Background: Stress is increasingly recognized as one of the most serious occupational health hazard for critical care nurses. Failure of proper stress management among nurses has a huge impact to health care delivery and quality outcome, it also results in increased health care cost hence poverty and poor economy.

Objective: The aim of this study was to identify prevalence of stress and various stressors, among the critical care nurses

Methods: A cross-sectional survey using quantitative research methods were used, where by 65 nurses who are working in critical care units were interviewed by using structured questionnaire consisting of close ended questions Since ICU nurses were 100 in number they were both targeted to be recruited from the study, but only 65 nurses were the one who returned the questionnaire. Validity and reliability of data questionnaires were tested to 10 ICU nurses at MOI. The collected data were analyzed using the computer software program (SPSS version 16.0).

Results: Study finding reveals that a variety of factors influence stress among ICU nurses at MNH. Among these, working environment, workload, interpersonal relationship as well as personal characteristics are identified to cause stress. Under personal characteristics knowledge and confidence as well as working as a team leader, performing or preparing sterile procedures like dressing, ETT suctioning, bronchoscope, CVP/AL insertion and dealing with machines that support patient breathing and others for hemodynamic monitoring $(67.7 \%, 72.3 \%$ and $78.5 \%$ respectively) are among the stressors mentioned. Additionally, out of work for the past six months is also reported of which $75 \%$ of respondents reported that they to be out of work for the past six months.

This is really a large number of staff since $25 \%$ of the remaining staff is most likely to be overloaded with work hence affecting productivity, performance and quality outcome of the services.

Conclusion and recommendation: It is concluded that work environment, work load, interpersonal relationship are among stressors which make nurses working in critical care unit very uncomfortable. It is strongly recommended that new strategies and measures should be put in place in order to improve ICU working environment as well as to improve psychosocial among nurses.
\end{abstract}

\section{LIST OF ABBREVIATIONS}

$\begin{array}{ll}\text { CCU: } & \text { Coronary Care Unit } \\ \text { DSM: } & \text { Dar es Salaam } \\ \text { HDU: } & \text { High Dependency Unit } \\ \text { ICU: } & \text { Intensive Care Unit } \\ \text { MNH: } & \text { Muhimbili National Hospital } \\ \text { MUHAS: } & \text { Muhimbili University of Health and Allied Sciences } \\ \text { SPSS: } & \text { Statistical Package for Social Sciences } \\ \text { TAU: } & \text { Texila American University } \\ \text { UK: } & \text { United Kingdom }\end{array}$


South American Journal of Nursing

Special Edition 2016

$\begin{array}{ll}\text { ETT } & \text { Endotracheal tube } \\ \text { CVC } & \text { Central Venous Catheter } \\ \text { ART } & \text { Arterial line } \\ \text { MOI } & \text { Muhimbili Orthopaedic Institute }\end{array}$

\section{Background information}

\subsection{Introduction}

Stress has been acknowledged as a significant problem in critical care units since their inception in the 1960 and arises from many different factors and conditions (Raja, Saadiah, Santhna, \& Nizam, 2007). On the other hand, critical care nurse may feel inadequate and stressed when faced with the enormous demands of the critical ill patient. The nurse is often required by the prescribed treatment to inflict discomfort on the patient e. g. suctioning, and is frequently faced with death as an outcome of intensive care.

This project therefore intents to assess factors associating with stress and stressors among nurses who are working in critical care units at Muhimbili National Hospital, Tanzania.

\subsection{Background information to problem}

Stress has been acknowledged as a significant problem in critical care units since their inception in the 1960 and arises from many different factors and conditions (Raja, Saadiah, Santhna, \& Nizam, 2007). Globalization and changes in the nature of health care delivery have resulted in increasing ICU nurse stress in developing countries. Stress in critical care nurses at present is already acknowledged as one of the epidemics of modern working life (Owolabi et al., 2012).Effect of work stressors to ICU nurses can be physical, psychological or behavioral changes (Raja et al., 2007).

A physical response to stress is associated with ulcers, cardiac disorders and skin rashes. Psychological response to stress is associated with outbursts of anger, unnecessary worries and frequent mood changes. Mood changes include tension, anxiety, fatigue and depression. Studies have indicated that increased stress can lead to job dissatisfaction, burnout, and precipitate attrition from critical care units, thereby increasing employment costs and can affect the competence and job performance of nurses and ultimately can have an impact on the patient and compromise patient's care (Jennings, 2008; Mbuthia, 2009; Poncet et al., 2007 \& Raja et al., 2007).

My experience working in the ICUs at Muhimbili National Hospital revealed a number of stress related problems among staff members of which the magnitude and origin has not been identified and documented. From experience, interpersonal conflicts (between nurses and between nurses and Doctors), physical illness, reduced morale to work, persistent lack of confidence among staff members and some saying that ICU is not a place to work for life (Jennings, 2008; Mbuthia, 2009; Raja et al., 2007) are also common conditions and complaints of ICU nurses at $\mathrm{MNH}$.

I have also come across some staff members who are almost burnout. Uncovering prevalence and the origin of stress among ICU nurses at MNH will raise awareness to the nurses that will make them think of developing effective stress coping skills for their health, and this may lead to improved job performance and patient's satisfaction.

The results will also increase awareness to the higher organization such as the Ministry of Health and Social Welfare (MOH \&SW) so that appropriate actions are done.

Working in critical care unit alone is a stressor because of its complexity, highly technical impersonal environment. Longtime stay in such unit can have adverse effect on the nurse hence poor performance and poor quality outcome. The critical care nurse may feel inadequate and stressed when faced with the enormous demands of the critical ill patient. The nurse is often required by the prescribed treatment to inflict discomfort on the patient e. g. suctioning, and is frequently faced with death as an outcome of intensive care. The nurse has to deal with emotions, feelings of the patient, significant others and her own. It is difficult for the nurse to escape as the patient require constant attention and close monitoring, hence 
critical care nurses are prone to stress and burnout. More often efforts to reduce stress is directed on the patient alone, leaving the nurse who also is equally stressed.

This project is aimed at identifying prevalence of stress and various stressors, among the critical care nurses and to find possible effective ways of how the nurse can cope with stress, and avoid adverse effects, A stressed nurse can never produce good quality outcome hence increased morbidity and mortality rate.

\subsection{Problem statement}

A number of studies revealed that nursing profession is an occupation with a huge number of stressful conditions (Duquette, 1994). Stress has a cost for individuals in terms of health, well-being and job dissatisfaction, as well as for organizations in terms of absenteeism and turnover, which in turn may impact the quality of patients care (ibid). Research studies on stress in nursing have identified a variety of stressors that depend upon the clinical speciality. However, some common stressors across nursing specialities include poor working relationships between nurses and doctors and other health care professionals, demanding communication and relationships with patients and relatives, emergency cases, high workload, understaffing and lack of support or positive feedback from senior nursing staff (McGrath, Reid and Boore, 1989).

Currently, Muhimbili National Hospital Management has instituted in-house training on caring of critically ill patients; this is all about improvement of quality of service among ICU nurses. Despite all the efforts made, and knowing the impact of stress among nurses, no training has been done to ICU nurses concerning, stress, stressors as well as how one can cope with stress while at work environment. Little is known as to why this is not happening while stress is known to impact quality of patients care as well ICU nurse. This study therefore ought to assess factors with stress and stressors among nurses working in critical care units at Muhimbili National Hospital.

\subsection{Objectives of the study}

This project was guided by the following broad and specific objectives;

\subsubsection{Broad objective}

The main objective of this project is to identify stressors and factors that increase stress levels among nurse who are working in critical care unit at Muhimbili National Hospital.

\subsubsection{Specific objectives}

The following specific objectives were attained,

a) To identify signs of stress on the ICU nurse at $\mathrm{MNH}$

b) To ascertain effects of stress on the nursing performance and quality outcome.

\subsection{Project questions}

a) What are the signs of stress among ICU nurses at MNH?

b) Why is it essential to identify effects of stress on the nursing performance and quality outcome?

\subsection{Rationale of the study}

This study poses useful information for both nursing administrators and nurses who work in ICUs. It increases the degree of awareness of stress related symptoms among nurses so that they can find coping skills, take personal measures to prevent symptoms of stress and deal with the factors that make the ICU environment stressful for nurses. It might also build foundation for future studies on stress among nurses in Tanzania. The study results may also help nursing administrators to deal with all the organizational factors that are associated with stress and apply appropriate actions. 
South American Journal of Nursing

Special Edition 2016

\subsection{Conceptual framework}

The conceptual model for this study is guided by ideas of Roy's Adaptation Model (Frederickson, Jackson, Strauman, \& Strauman, 1991). Roy assume that human beings are constantly exposed to environmental stimuli on which, if one adapt positively will have enhanced growth and competence (health) and for those with negative adaptation will end up with burnout (illness). Interpersonal conflict, work overload and its demands, personal characteristics, management issues and ICU environment are among the postulated sources of stress (stimuli) to ICU nurses in the previous studies (Jennings, 2008; Ling, Taiwanai, Lai, \& Peng, 2005; Mbuthia, 2009).

This model has been used to guide the researcher in literature review, development of study tool and discussion of the results.

Figure 1.1 herein, represents the said model;

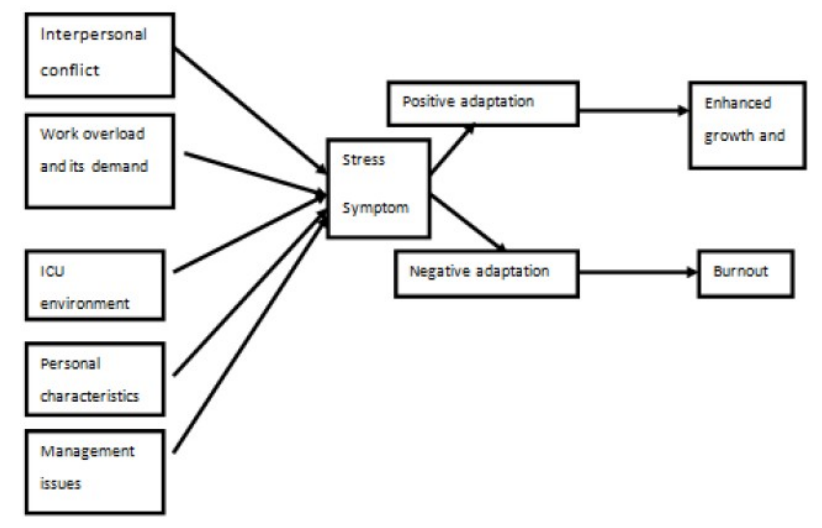

Figure 1.1: Conceptual framework on Factors associated with stress.

From Figure 1.1 above, each factor has a meaning in this framework, the following are the description of each factor;

Interpersonal relationship as stressor has been assessed by asking nurses whether they had conflict with fellow nurse, supervisor or a doctor in the previous six months including the date of the study.

Work overload and its demands has been explained by the number of patients taken care of by a nurse per shift; so nurses were asked whether they are comfortable or not to take care of two to three patients.

ICU environment is also a source of stress, noise from alarms of machines connected to the patient and those coming from systems not connected to the patient; Climatic condition (cold) of ICU is also very uncomfortable to some staff members leading to physical inactivity and reduced work performance; inadequate safety due to slippery flows in some units; lack of user friendly equipment like oxygen sources; continuous exposure to death and dying patients, human suffering, and despaired relatives who constantly need psychological and emotional support are also very Stressful situations to ICU nurses.

Personal characteristics can also determine whether a nurse is being stressed or not. Gender, age, level of education, work experience, marital status and having ICU trained or not are elements of personal characteristics.

Management issues were assessed for whether being a stressor or not by asking nurses about their perception on the roles they perform according to their education levels; also nurses were asked about how they feel when they are taking care of a critically ill patient who sometimes needs vital sign recording at 15 minutes interval, at the same time required to trace other paramedics who sometimes take hours to respond. This is very common at Muhimbili hospital, shortage; poor ICU organization; and inadequate workers motivation may be the reasons for that and poor remunerations.

Positive adaptation means constructive response to sources of stress that lead to personal growth and enhanced competence. 
Negative adaptation means destructive response to stressors that lead to burnout.

\subsection{Definition of the key terms}

\section{Critical Care Unit:}

This is also known as intensive care unit, intensive therapy unit or intensive treatment unit, it is a special department of a hospital or health care facility that provides intensive care medicine.

\section{Stress:}

Is a state of psychological and/or physiological imbalance resulting from the disparity between situational demand and the individual's ability and/or motivation to meet those demands?

\section{Stressors:}

These are physical, psychological, or social force that puts real or perceived demands on the body, emotions, mind or spirit of an individual.

\subsection{Organization of the paper}

This project has been systematized into five chapters and every chapter is more divided into several subdivisions. The first chapter of this study gives out introduction and background to the study. In this chapter the study also poses the objective of the study, research question followed by relevance of the study as well as the conceptual framework.

Chapter two of this study reviews different literatures concerning stress among nurses working in critical care units. It well shows general overview of stress and stressors further break it into stress and stress factors among nurses in Tanzanian context and empirical related literatures as far as stress among healthcare service delivery is concerned. This section is followed by research gap and a short summary of the chapter in the end.

The third chapter provides methodology which was used to gather information from study respondents, study design, population of the study, ethical clearance as well as data analysis procedures.

Chapter four of this study provides the analysis and discussion of the study findings. The analysis and discussion was done based on the objectives of the study as related to the empirical literature. The final chapter is the fifth chapter that provide conclusion of the whole project and the recommendations as far as factors causing stress among ICU nurses is concerned.

\section{Literature review}

\subsection{Introduction}

This chapter presents literature used in this project. It explains stress overview as well as available literatures that some scholars have written concerning stress and stressors. It is well showed how the research problem is related to previous studies. It also encompassed the causes of stress as well as the effects of stress among nurses who are working in intensive care units.

\subsection{Stress overview}

Stress is an essential part of human beings' mechanisms and can be considered a stimulant, a source of satisfaction and balance. It is the adaptive response to any requirement the environment or the person him/herself poses (Vaz Serra, 2005). Stress is the condition that results when person/environment transactions make the subject feel a discrepancy between the demands of a given situation and biological, psychological or social resources (Santos, 1998).

It is important to recognize that stress is a state, not an illness, which may be experienced as a result of an exposure to a wide range of work demands and in turn can contribute to an equally wide range of outcomes (Doherty, 1998), which may concern the employee's health and be an illness or an injury, or changes in his/her behavior and lifestyle. 
South American Journal of Nursing

Special Edition 2016

\subsection{Stress and stressors}

\subsubsection{Work load and demands}

There is a lot of physical labor in critical care such as turning patients, suctioning etc hourly medications and observations resulting in exhaustion of the nurse and ineffective coping. Increased demands from the critically ill patient and significant others attributes largely to stress among nurses (Roberts et al.,) Lack of human resources significantly attributes to increased workload and low nurse patient ratio, hence one nurse cares more than one patient, the ideal nurse patient ratio in ICU stands on 1:1 and HDU

- Interpersonal relationships

- Ineffective behaviors Increased Demand for energy

- Decreased

- Tension state

- Effective behaviors

Criticare nursing is a multi-displinary collaboration, it needs interaction with others, subordinates, seniors, doctors and other paramedics. Negative interaction with each other result is good source of stress (Bakker et al 2005). When nurses fail to appreciate each other's work or behavior conflicts occurs, negative attitude such as gossiping, constant criticisms, arguments, framing and belittling. The recipient of these attacks often suffer from humiliation, low self-esteem, fatigue and low morale resulting in stress and burnout (Mbuthia 2009).

Teamwork and cooperation between nurses and doctors in patient care is of paramount, when the two cooperates and discuss the care, setting goals together, the nurse feels respected and worthy hence reducing stress on her. Raja et al concluded that verbal attacks and aggression from doctors brings about violence and reduce morale, causing stress among nurses.

\subsubsection{Management issues}

Nurse Managers can greatly attribute to stress among nurses if they fail to create a conducive environment to the subordinates. Lack of effective communication skills, poor decision making, and critical thinking by nurse managers causes stress among nurses. Respective clinical supervision reduce stress (Bennett, LOWE, Mathews Dourali, \&Tatters et al 2001). Effective clinical supervision brings about minimal stress leading to job satisfaction and retention of nurses ( Dill, 2008).

\subsubsection{ICU environment}

The environment ion ICU is noisy from alarms and noise is a stressor not only to the nurse but the patient as well. Alarms should be kept under control and volume minimized. The cold temperatures in ICU makes the environment to be unfavorable to the nurse who is by the bed side all the time resulting in frequent attacks of cold and other diseases associated with low temperature

\subsection{Cause of Stress among nurses}

Job design and workload Interpersonal relationships at work Relationships with patients and their families Work organization and management of work Technical aspects of nursing Personal dealing with death and dying, ambiguity conflict with other staff inadequate preparation for dealing with emotional needs of family lack of staff support (RN shortage) and resources concern about treatment and patient care Concern about technical knowledge and skills.

Moreover, age and shift working is also reported among causes of stress among nurses. Nurses with age between 35 to 54 reporting high work stress; the highest among age groups Health care providers who worked 35 or more hours per week were much more likely than those working fewer than 35 hours per week to report high stress. Health care providers whose schedule was other than a regular daytime shift were more likely to report high work 
stress.

In giving out the description of the causes of stress, each stressor is expressed herein;

\subsubsection{Working environment}

According to Moustaka, et Al., (2010) as cited in a study done by Gray-Toft and Adderson (1981), they identified three stressful situations that affects work performance; these are physiological, psychosocial and social environment. However, according to European Organization for Safety and health at work (2002), reported that working conditions such as the wrong ventilation, lighting and the inadequate temperature levels are among the potential work-related stressors among nurses. On the same note Cooper (1998) support that difficulties in coping with stress combined with psychological or emotional instability could lead to violence.

Furthermore, healthcare institutions are of different in sizes and nature, and nurses are confronted with different work tasks and working hours; nightshifts, understaffing and stress related situations as well as the suffering and death of patients (Cooper, 1998).

\subsubsection{Interpersonal relationship}

Blair and Littlewood (1995) emphasized that work relationships are potential stressors. Two sources of stress in this field are the conflicts with co-workers and the lack of staff support. Another assessment done by Sveinsdottir, et. al., (2006) showed that lack of social support from colleagues and superiors and less satisfaction with the head nurses contributed significantly to the appearance of stress. Similarly, other study identified the negative effect of lack of understanding and support from their managers, on workers' stress.

\subsubsection{Nature of nursing}

Nature of the job is another cause of stress among nurses because some people just decided to enter this profession since they wanted employment, but once they faced the reality of the job they soon realize that is not the way they thought it would be (Sky Hudgins, 2008). According to Moustaka, et. Al., (2010) as cited in Marshal (1980), stress is taking its charge considering the nature of nursing tasks and the involvement with death and dying people hence those who enrolled to the profession wrongly face the consequences.

\subsection{Effects of stress on health}

Plainly speaking, there are appears to be general agreement that the experience of workrelated stress generally detracts from the quality of nurses' working lives, social life, increases minor psychiatric morbidity, and may contribute to some forms of physical illness (Khai and Josh, 2007). It is also true, that stress can have far reaching consequences for nurses which is why stress management for nurses is so important, since occupational stress has been found to be one of the major work related health problems for the workers (Gray, 2000) as well as one of the greatest forced cost for the hospitals (Aike, et al., 2001).

Effects of stress differs with individuals, if it gets out of control it may harm one's health, disturbs the nurse patient relationships hence poor patient care, social relationships, poor team work and poor performance in general. This literature review is guided by the conceptual framework with factors associated with and effects of stress on the nurse, also included are the physiology of stress according to Hans Seyle.

\subsection{The physiology of stress}

The experience of stress is accompanied by many physiological changes. Selye's General Adaptation Syndrome. Hans Selye, a pioneer in the field of stress research, proposed that stressors of many different kinds result in a nonspecific bodily response. He said the body's stress response consists of a general adaptation syndrome, which has three stages: alarm, resistance, and exhaustion.

\section{Stage 1}

In the alarm stage, an organism recognizes a threatening situation. The sympathetic 
nervous system activates, giving rise to the fight-or-flight response. Digestive processes slow down, blood pressure and heart rate increase, adrenal hormones are released, and blood is drawn away from the skin to the skeletal muscles.

\section{Stage II}

The resistance stage occurs when stress continues. Physiological arousal stabilizes at a point that is higher than normal.

\section{Stage III}

If stress is prolonged, organisms reach the exhaustion stage. The body's resources run out, and physiological arousal decreases. In this stage, organisms become more susceptible to.

\subsection{Related literature on stress among nurses}

In a study done in UK (1993), Musculo-skeletal disorders were the most common cause of ill-health among all respondents (42\%), followed by stress and depression. Nurses were among the highest groups who reported significantly raised rates of stress and depression.

\subsection{Research gap}

Many researchers have been done on stress and stressors among nurses/healthcare providers worldwide. However, taking into consideration the significance stress, then the available researches has not provided clear insight of on strategies which should be done to encounter the same in Tanzania, therefore this research project highlights the problem and its solution on the aspect stress and solution to the challenges facing critical care nurses.

\subsection{Chapter summary}

Chapter two of this project gives out the details of stress overview as well as causes of stress among nurses. This was done determinedly so as to gain a comprehensively forthcoming and facts information regarding stress with the urge of answering the research questions at hand. The chapter presents very well the theories related to the study.

\section{Methodology}

\subsection{Introduction}

This chapter presents description of study design, study area, study population, sample estimation, Inclusion and exclusion criteria, sampling procedures, data collection procedures. Study variables data management, analysis and ethical consideration.

\subsection{Study design}

A research design is the framework or plans, used to guide in collecting and analyzing data (Churchill, 1995). It is the blueprint that has to be followed in completing a study ${ }^{41}$. Indeed, research design is like an architect's blueprint for the house through which all major parts of the research will be guided (ibid) ${ }^{\circ}$ With this regard, descriptive cross sectional was opted. It is a design concerned with determining the frequency with which something occurs or the relationship between two variables (ibid).

Descriptive study, is rigid in methodology and requires a clear statement of who, what, when, why, and where of the research (ibid). Applying a descriptive research in this study, a Cross -sectional Analysis of case study was applied. It was applied for a snap shot study of assessing factors associating with stress among nurses at MNH. Descriptive research design dealt with the frequency in which stress occur and prevail. Importantly, it was used for explaining relations between variables such management issues, work environment and stress.

\subsection{Setting}

The study was conducted at Muhimbili National Hospital in Dar es salaam, Tanzania, East Africa. The hospital has a bed capacity of 1500 beds and has two functional ICU's plus a high dependency unit, Main ICU with 6 beds, Cardiac ICU with 10 beds, coronary care (CCU) with 8 beds and HDU with 15 beds. This hospital was selected since it the places where I 
work, therefore giving me the advantage of carrying out my project, also it is the one and only national, referral, and largest teaching hospital in the country.

\subsection{Population}

Study population is the entire aggregation of cases in which researcher is interested in (Polit and beck 2000). In this study therefore; all nurses working with the Muhimbili national hospital`s critical care units (ICU+HDU) were recruited from the study.

\subsection{Sampling technique and sample size}

Since it is hard for an investigator to cover the entire population, sampling is one of the best methodical practices for selecting a group of individuals. Simple random technique was employed to select study participants.

Simple random technique is opted because every object has the same possibility to be chosen. According to Kothari (2000) Simple random sampling is a process of selecting a sample at random from the sampling frame. Each member of the population has an equal chance of being selected for the sample. Simple random sampling maintains the original sampling frame, but the number of elements available to be drawn decreases as each element of the sample is removed before the next choice is made.

\subsubsection{Sample size calculation}

Sample size refers to the number of items to be selected from the study setting to represent a sample. Nassiumas (2000) formula was used to estimate the sample size; with Nassiumas formula, if population is less than a thousand, a researcher can take the whole population. In this project therefore, all 100 nurses were recruited in the study.

\subsection{Sampling procedure}

Convenient sampling technique was used to recruit study participants in this project. This method was chosen due to time constraints and limitation of resources. Convenience sampling was used when a researcher has reason to believe that the population that is being sampled is either homogeneous or else has characteristics being measured that are so randomly distributed that the outcome would not be materially affected by more sophisticated methods of sampling (Dorofeev \& Grant 2004). Because respondents in this study were nurses who are working in critical care units, all of them were recruited in this study. A total of 100 questionnaires were distributed to all critical care nurses.

\subsection{Data collection technique and data collection tools}

\subsubsection{Sources of data}

Two sources of data were employed in this study. These are primary data and secondary data. According to Kothari (2008), secondary data refer to the data which are available; they are already been collected and analyzed by someone else. Secondary data may be found in published or unpublished data which involve the data from the books, journals, gazette, and articles as well as from the internet. Secondary data can be easily gathered and they are inexpensive compared to primary data.

Primary data on the other hand, are those data which are collected afresh and for the first time and thus happen to be the original data (Kothari, 2008).

\subsubsection{Data collection tools}

There are several collection tools particularly in collecting primary data since secondary data are being collected by merely compilation of the available data. These tools are questionnaires, interview guide questions, observation. This study employs questionnaire as well as using observation hence these two tools were explained below; 
South American Journal of Nursing

Special Edition 2016

\subsubsection{Questionnaire}

This is the most popular tool for data collection. According to Kothari (2008), questionnaire consist a number of questions which are well typed and printed in a definite set of forms (see Appendix A). The questionnaires can be mailed to the study participant or can be hand delivered by the researcher or research assistant. In this study all questionnaire were hand delivered.

\subsection{Inclusion criteria}

Inclusion is simply known as the "somebody or something included" in a research the term inclusion criteria entails the set or guidelines to be considered or met when one is to be included in the study.

In this study therefore, inclusion criteria used was the availability of all the professional nurses at the time of the study and agree to participate in the study.

\subsection{Exclusion criteria}

Exclusion on the other hand meant "to eliminate or keeping out". In this perspective the exclusion criteria are the guidelines that give identification of who is not supposed to participate in the study.

Exclusion criteria was absence of nurses as well as those who decline to participate in the project.

\subsection{Ethical consideration}

The project proposal was submitted to TAU for learning purposes. Furthermore, verbal communication with unit managers for consent to do the study in each unit was done and participants were informed to sign a consent form to participate in the study. Decision to participate was free, nobody was coerced in participating and no forms of payment were given. Participation was purely voluntary; no harm is expected during the study and for confidentiality no names mentioned, only code numbers were used.

\subsection{Validity and reliability}

Validity and reliability are the crucial elements as far as research is concerned. Conclusions drawn from analysing survey data are only acceptable to the degree to which they are determined valid.

In order to confirm the strength of the research tool, 10 drafts of questionnaires were distributed to the Muhimbili Orthopaedic Institute ICU nurses for pre-testing so as to make sure the strong points are met and its uniformity. This in turn helped the researcher to modify questions and authenticate the research tools before actual data gathering.

\subsection{Data analysis}

Data analysis commences immediately after data collection. All collected data were grouped into required categories prior to analysis. Statistical Package for Social Sciences (SPSS version 16.0) was used to analyse collected data. Obtained data were then presented into histograms as well as tables.

\subsection{Limitation of study}

a) Since the study was done in one hospital alone, therefore; the findings of this study are limited to critical care nurses who are working at $\mathrm{MNH}$ only.

b) The use of convenience sampling is always accompanied by some potential for bias.

c) Since this is a cross-sectional study in nature, meaning that it takes place at one point in time. Such a study does not take into account staffing changes, managerial changes or the patient census of the units at the time when the study is conducted, and these factors may exert an impact on the responses of the nurses.

d) In self-report, participants may exaggerate stress symptoms in order to make the 
situation worse or may under-report the severity or frequency of the problem/event.

\subsection{Dissemination of findings}

The result was disseminated to TAU Authority and to Muhimbili ICU management for planning strategic management in copying with stress among nurses. This entails that, issues of absenteeism, poor cooperation as well as interpersonal relationships will be dealt upon.

\section{Presentation of the findings and discussion}

\subsection{Introduction}

This chapter presents the study findings and analysis made on data which were congregated during data collection. Principally, the section above all deals with evidences and statistics revealed by means of the data. Subsequently, it infers the gathered data in detail, in order to present main findings of the study so as to encounter objectives of the study. In doing so, all the research questions meet their answers. In short this chapter delivers a comprehensive assessment of the factors associating with stress and stressors among nurses working in critical care units at $\mathrm{MNH}$.

In this regard, the analysis of this research sought to answer two research questions;

a) What are the signs of stress on the ICU nurse at MNH?

b) How does stress affects performance and quality outcome of the services delivered by ICU nurse at MNH?

\subsection{Response rate}

According to Buckingham and Saunders (2004) response rate is usually refers to the proportional of respondents in the sample who complete and return a questionnaire.

As such, any conclusion drawn by the researcher is based on a sub-sample of the original sample (Viswesvaran, et al., 1993). Table 4.1 below presents the questionnaire sent out and those which were returned back.

Table 4.1 Distribution of Questionnaire $\mathrm{n}=100$

\begin{tabular}{|l|l|l|}
\hline Questionnaire Sent & Questionnaire Returned & Response Rate \\
\hline 100 & 65 & $65 \%$ \\
\hline
\end{tabular}

Source: Researcher, 2013

From the table above 100 questionnaires were distributed to study respondents but only 65 were returned back, making a response rate of $65 \%$. The obtained response rate is considered sufficient as per Polit and Beck (2004). According to them a response rate of $65 \%$ or more is usually considered sufficient for most research purpose.

\subsection{Characteristics of the respondents}

A brief personal profile of respondents is provided in this part of the capstone project. This information was obtained from the questionnaire. Personal information includes respondent age and gender is indicated in Table 4.2 and Table 4.3 below;

Table 4.2: Respondents Demographic Characteristics

\begin{tabular}{lcc}
\hline & $\mathrm{No}$ & percentage \\
\hline GENDER & $\mathrm{N}=65$ & $\%$ \\
Male & 16 & 24.6 \\
Female & 49 & 75.4 \\
\hline MARITAL STATUS & $\mathrm{N}=65$ & $\%$ \\
Single & 26 & 40.0 \\
Married & 38 & 58.5 \\
Widow & 1 & 1.5 \\
\hline PROFESSIONAL LEVEL & $\mathrm{N}=65$ & $\%$
\end{tabular}


South American Journal of Nursing

Special Edition 2016

\begin{tabular}{lcc} 
Enrolled Nurse & 8 & 12.3 \\
Diploma Registered Nurse & 45 & 69.2 \\
Advanced Diploma Nurse & 4 & 6.1 \\
Degree Registered Nurse & 5 & 7.6 \\
Specialist Nurse & 3 & 4.6 \\
\hline RESPONDENTS AGE & $\mathrm{N}=65$ & $\%$ \\
$<25$ & 6 & 9.2 \\
$26-35$ & 43 & 66.1 \\
$36-44$ & 11 & 16.9 \\
46 and above & 5 & 7.7 \\
\hline
\end{tabular}

Table 4.3: Training on ICU and years working in ICU

\begin{tabular}{lll}
\hline TRAINING IN ICU & $\mathrm{N}=65$ & $\%$ \\
Yes & 7 & 10.8 \\
No & 58 & 89.2 \\
\hline YEARS WORKING IN ICU & $\mathrm{N}=65$ & $\%$ \\
$<1$ & 4 & 6.1 \\
$1-3$ & 27 & 41.5 \\
$4-6$ & 19 & 29.2 \\
$7-9$ & 9 & 13.8 \\
10 and above & 6 & 9.2 \\
\hline
\end{tabular}

As illustrated in table 4.2, the age distribution was obtained. Majority of study participants were having the age between $26-35$ years $(66.1 \%)$. From these findings it is noted that 66.1 $\%$ of study respondents are many compared to other age groups, this could be attributed due to the middle age where these generation are energetic and that can move quickly depending with the nature of the work. Gender wise, the study reveals that females were many in this profession as compared to their counterparts' males ( $75.4 \%$ and $24.6 \%$ respectively).

Profession wise, the findings revealed that majority of study respondents are diploma registered nurse as presented by $69.2 \%$. Consideration was also given to the respondents who attained ICU training, the findings revealed that only 7 (10.8\%) respondents had attained special training on ICU but the good majority $58(89.2 \%)$ had not received special training on ICU. From researcher point of view it is wise for critical care nurses to be trained on handling critical care patients as well as how to manage stress while working under critical care unit. This would develop enhance confidence and capabilities to interconnect doctors and other nurses, including interns as well as other nurse students, this in turn will cultivate a strong teamwork.

\subsection{Signs of stress on the ICU nurse}

Signs of stress among nurses were examined as a part of factors that can hinder provision of service among patients. This is well presented in Table 4.4 below;

Table 4.4: Signs of Stress among ICU nurses $n=65$

\begin{tabular}{lcc}
\hline \multicolumn{3}{c}{ Signs and Symptoms of Stress } \\
\hline Signs & Yes & No \\
\hline Back pain & $55(84.6 \%)$ & $10(15.4 \%)$ \\
Headache when you are at work place & $54(83.1 \%)$ & $11(16.9 \%)$ \\
Chest Pain & $49(75.4 \%)$ & $16(24.6 \%)$ \\
Stomach upset & $45(69.2 \%)$ & $20(30.8 \%)$ \\
Weight gain/loss & $55(84.6 \%)$ & $10(15.4 \%)$ \\
Poor concentration at work & $45(69.2 \%)$ & $20(30.8 \%)$ \\
Bouts of anger easily & $42(64.6 \%)$ & $23(35.4 \%)$ \\
Self - pity & $44(67.7 \%)$ & $21(32.3 \%)$ \\
Feeling tired even with no significant work & $48(73.8 \%)$ & $17(26.2 \%)$
\end{tabular}


With respect to the signs which can cause stress among nurses who are working in critical care units at MNH, it is well seen that the good majority of the ICU nurses working in ICU units are stressed at least by one of the mentioned signs. This is well noted since at each sign mentioned and for those who have 'yes' as response occupied more than $60 \%$.

\subsection{Effects of stress on the nursing performance and quality outcome}

It is well believed that stress can hinder performance and quality outcome of any service rendered. With this regard, the study participants were asked if at all they were out of work for the past six months, the findings are presented in Figure 4.1 below;

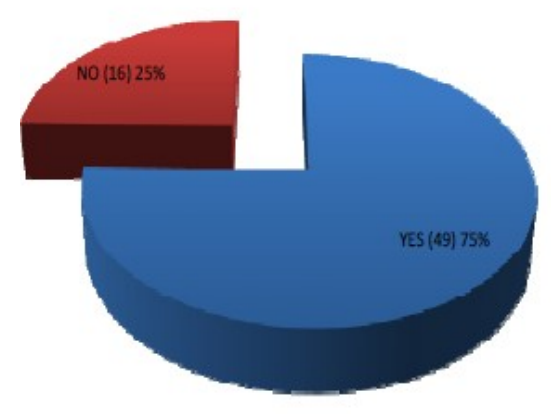

\section{Figure 4.1: Out of work for the past six months}

As the figure depicts $75 \%$ of respondents reported that they were out of work for the past six months. This is really a large number of staff since $25 \%$ of the remaining staff is most likely to be overloaded with work hence affecting productivity, performance and quality outcome of the services. This is in line with the study done in America which revealed the similar results. The same is also true from the study done in Malaysia.

Moreover, respondents who were not at work for the past six months were asked to state the reasons which persuaded them not to reach at work for the said months; their reasons are presented in Figure 4.2 below;

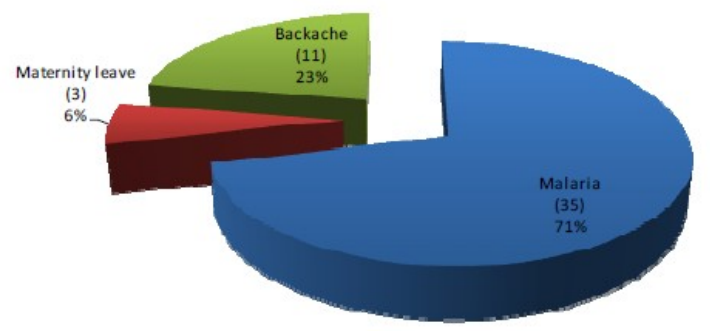

Figure 4.2: Reasons for being out of work for the past 6 months

As illustrated in figure 4.2 above, malaria, backache and maternity leave are the reasons which are mentioned $(71 \%, 23 \%$ and $6 \%$ respectively). Malaria is taking the biggest percentage because it is a tropical disease mostly affecting Sub Saharan Africa states. Secondly, the nature of work involving shifts which might take at times longer work schedules leading to exhaustion and fatigue

\subsubsection{ICU environment}

ICU environment was among the factors that lead to stress among nurses. With this respect respondents were asked if machines connected are causing disturbances or if they are uncomfortable with cold temperature. The findings are presented in Table 4.5 below;

Table 4.5: ICU Environment $n=65$ 


\begin{tabular}{lll}
\hline & Yes & No \\
\hline Disturbance with machine & $51(78.5 \%)$ & $14(21.5 \%)$ \\
Uncomfortable with cold temperature & $59(90.8 \%)$ & $6(9.2 \%)$ \\
\hline
\end{tabular}

As illustrated above; findings reveal that machines as well as cold temperature in ICU are likely to cause stress since response from respondents is higher $(78.5 \%$ and $90.8 \%$ respectively). From the researcher's viewpoint, it is seen that ICU environment was quietly responsible in enhancing stress among ICU nurses. These findings are in line with the study done by European Organization for Safety and health at work (2002) that working conditions such as the wrong ventilation, lighting and the inadequate temperature levels are among the potential work-related stressors among nurses.

\subsubsection{Work load demand}

Consideration was also given on work load demand. The findings are well presented in Table 4.6 below;

Table 4.6: Work load demand $\mathrm{n}=65$

\begin{tabular}{lll}
\hline Work load demand & & \\
\hline & YES & NO \\
\hline Overwhelming caring for critically ill patients & $54(83.1 \%)$ & $11(16.9 \%) 42$ \\
Stressed caring for dying patients (Resuscitation) & $60(92.3 \%)$ & $5(7.7 \%)$ \\
\hline
\end{tabular}

Table 4.6 above revealed that $83.1 \%$ respondents are overwhelmed caring for ill patients while $92.3 \%$ respondents were stressed caring for dying patients. With these findings it is clearly seen that there is association between stress and work load.

\subsubsection{Management issues}

Relationship between stress and management issues was also considered. The research was in opinion to know the association between stress and management issues as presented in Table 4.7 below;

Table 4.7 Management Issue $n=65$

\begin{tabular}{lcc}
\hline Issues & & \\
\hline & YES & NO \\
\hline Stressed caring more than one patient & $61(93.8 \%)$ & $4(6.2 \%)$ \\
Stressed tracing other paramedics? & $52(80.0 \%)$ & $13(20.0 \%)$ \\
Long shifts (shortage of staff) & $58(89.2 \%)$ & $7(10.8 \%)$ \\
Lack of identified/recognized job description & $60(92.3 \%)$ & $5(7.7 \%)$ \\
\hline
\end{tabular}

Findings under current project revealed that all the issues stressed above are the factors that are likely to cause stress. This is well presented since both issues mentioned occupied $80.0 \%$ of "yes" and above response.

\subsubsection{Interpersonal relationship}

Interpersonal relationship was also considered among the factors that influences stress among nurses working at critical care at MNH. The analysis of this capstone project is presented under Figure 4.3 below;

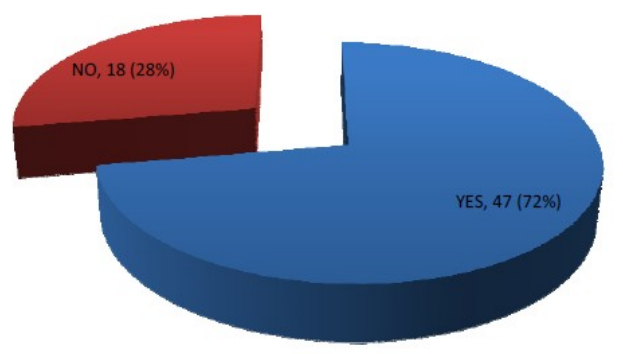




\section{Figure 4.3: Working in the presence of doctors}

Figure 4.3 above revealed that $72 \%$ of respondents reported that working in the presence of doctors/consultants and administrators likely to cause stress while $28 \%$ of study respondents denied.

\subsubsection{Personal characteristics}

Personal characteristics were also considered. The research was in opinion to know how personal characteristics can cause stress among nurses as presented in Table 4.8 below;

Table 4.8: Personal Characteristics $n=65$

\begin{tabular}{lll}
\hline Characteristics & YES & NO \\
\hline Working as a team leader (confidence \& knowledge) & $44(67.7 \%)$ & $21(32.3 \%)$ \\
\hline Performing sterile procedures (ETT, CVP, etc.) & $47(72.3 \%)$ & $18(27.7 \%)$ \\
Hemodynamic monitoring (knowledge \& confidence) & $51(78.5 \%)$ & $14(21.5 \%)$ \\
Characteristics & YES & NO \\
\hline
\end{tabular}

As revealed from Table 4.8 above, majority of respondents reported that personal characteristics likely to cause stress and agreed that knowledge and confidence working as a team leader, performing or preparing a sterile procedures like dressing, EET suctioning, bronchoscope, $\mathrm{CVP} / \mathrm{AL}$ insertion as well dealing with machines that support patient breathing and others for hemodynamic monitoring $(67.7 \%, 72.3 \%$ and $78.5 \%$ respectively).

\section{Conclusion and recommendation}

\subsection{Introduction}

This chapter presents the conclusion and recommendation for further studies.

\subsection{Conclusion}

From the aforementioned discussion it is well noted that many factors included work environment, work load, interpersonal relationship as well as personal characteristics are among stressors which make nurses working in critical care unit very uncomfortable.

Clearly stated and researched; there a number of symptoms which causes stress among nurses. Among symptoms mentioned are, headache when at work place, back pain, chest pain, stomach upset, weight loss, bouts of anger easily was commonly cited, added is staff being out of work for the past six months. The common reason mentioned is malaria which has taken higher percentage as well as back ache. Actually this undermine the required service being offered accordingly, since shortage of staff by that particular time made other staff being overloaded with work. Additionally, poor organization amongst staff was also mentioned.

Basically, workload demand as well as ICU environment was practically mentioned among stressors, equally important management issues was also mentioned and prove to among stressors. On the same note, respondents reported that personal characteristics likely to cause stress included are concrete knowledge and confidence working as a team leader, performing or preparing a sterile procedures like dressing, ETT suctioning, bronchoscope, CVP/AL insertion as well dealing with machines that support patient breathing and others for hemodynamic monitoring.

\subsection{Recommendation}

From the above project results, the following are recommendation which should be taken into immediate action;

\section{- Absent from work}

Since the study revealed that, majority of staff are not able to come at work due to unavoidable reasons especially ill health, and malaria taken the biggest percent $(71 \%)$. It is recommended that, fumigation as well as prophylaxis measures should be 
South American Journal of Nursing

Special Edition 2016

taken so as to avoid such occurrences.

\section{- Good Coordination and team building}

Research also revealed that there is poor coordination between staffs; ICU Unit team should recommend on the good coordination between staff which will enhance better working environment to each other as a results the whole work will be done as planned/scheduled.

\section{- Training on ICU speciality}

Study findings revealed that out of 65 nurses participated in the study, only 7 $(10.8 \%)$ had ICU training and the rest $58(89.2 \%)$ did not have special training on ICU training. With this regard, it is highly recommended that critical care nurses should be imparted with training on ICU theories and consequences of caring critically ill patients. This in turn will reduce stress for those who are scared caring for dying patients.

\section{References}

[1.] Bakker, A. B., Le Blanc, P. M., \& Schaufeli, W. B. (2005). Burnout contagion among intensive care nurses. Journal of Advanced Nursing, 51(3), 276-287.

[2.] Bennett, P., LOWE, R., Matthews, V., Dourali, M., \& Tattersall, A. (2001). Coping, managerial support and work demand. Stress and Health, 17, 55-63.

[3.] Cole, A. 1992. Stress Pressure Point. Nursing Time. 87, 21-23.

[4.] Curtis, R., \& Kathleen, P. (2007). Is There an Epidemic of Burnout and Post-traumatic Stress in Critical Care Clinicians? American journal of respiratory and critical care medicine 175: 634-636.

[5.] Churchill G A, (1995). Basic Marketing Research. New York: Havcourt Brace College Publishers.

[6.] Churchill G. A and Lacobucci D, (2002). "Marketing Research". Methodological Foundations. 8th Edition. New York: Havcourt Brace College Publishers

[7.] Dorofeev, S., \& Grant, P. 2004. Statistics for real life sample surveys: non simple random samples and weighted data. Cambridge. Cambridge University Press.

[8.] Frederickson, K., Jackson, B. S., Strauman, T., \& Strauman, J. (1991). Testing Hypotheses Derived from the Roy Adaptation Model. Nursing Science Quarterly, 4(4), 168-174.

[9.] Gholamzadeh, S., Sharif, F., \& Rad, F. D. (2011). Sources of occupational stress and coping strategies among nurses who are working in Admission and Emergency Department in Hospitals affiliated to Shiraz University of Medical Sciences, Iran. Iranian Journal of Nursing and Midwifery Research, 16(1), 42-47

[10.] Jennings, B. (2008). Work Stress and Burnout among Nurses: Role of the Work Environment and Working Conditions - Patient Safety and Quality - NCBI Boo16

[11.] Ling, L., Taiwanai, S., Lai, W. S., \& Peng, L. C. (2005). Perception of Stress in an Intensive Care Unit Setting among Nurses working in ICU and General ward.

[12.] Linden, D. V. D., Keijsers, G. P. J., Eling, P., \& Schaijk, R. V. (2005). Work stress and attention difficulties: An initial study on burnout and cognitive failures. Work \& Stress, 19(1), 23-36.

[13.] Mealer, M. L., Shelton, A., Berg, B., Rothbaum, B., \& Moss, M. (2007). Increased Prevalence of Post-traumatic Stress Disorder Symptoms in Critical Care Nurses. American Journal of Respiratory and Critical Care Medicine, 175(7), 693-697.

[14.] Melinda, S., Robert, S., \& Jeanne, S. (2012). Understanding Stress: Symptoms, Signs, Causes, and Effects.

[15.] Michie, S. (2002). Causes and management of stress at work. Occupational and Environmental Medicine, 59, 67-72.

[16.] Mims, A., \& Stanford, T. (2004). Stress and Burnout among Critical Care Nurses, 3.

[17.] Owolabi, A. O., Owolabi, M. O., Ola Olorun, A. D., \& Olefin, A. (2012). Work-related stress perception and hypertension amongst health workers of a mission hospital in Oyo State, southwestern Nigeria. African Journal of Primary Health Care \& Family Medicine, 4(1), 7 pages.

[18.] Peltzer, K., Shisana, O., Zuma, K., Van, W., \& Zungu, D. (2009). Job stress, job satisfaction and stress-related illnesses among South African educators.

[19.] Poncet, M. C., Toullic, P., Papazian, L., Kentish-Barnes, N., Timsit, J.-F., Pochard, F., Chevret, S., 
et al. (2007). Burnout Syndrome in Critical Care Nursing Staff. American Journal of Respiratory and Critical Care Medicine, 175(7), 698- 704.

[20.] Preto, V.A. \& Pedrao, L.J. (2009).Stress among nurses who work at the Intensive Care Unit. 43(4),838-45.

[21.] Polit, D.F. \& Beck, C.T. 2004. Nursing research: principles and methods (7th Ed.). Philadelphia: Lippincott Williams \& Wilkins.

[22.] Raja, L., Saadiah, T., Santhna, L. P., \& Nizam, J. (2007). Prevalence of Stress and Coping Mechanism among Staff Nurses in the Intensive Care Unit. Med \& Health, 2(2), 146-153. 